\title{
Editorial \\ Epidemiology, costs, and the economic burden of fibromyalgia
} Michael Spaeth

Rheumatologische Schwerpunktpraxis, Bahnhofstraße 95, 82166 Graefelfing, Munich, Germany

Corresponding author: Michael Spaeth, dr.spaeth@mac.com

Published: 30 June 2009

Arthritis Research \& Therapy 2009, 11:117 (doi:10.1186/ar2715)

This article is online at http://arthritis-research.com/content/11/3/117

(C) 2009 BioMed Central Ltd

See related research by Sicras-Mainar et al., http://arthritis-research.com/content/11/2/R54

\begin{abstract}
The assumption that fibromyalgia is associated with a major impact on the utilization of both healthcare and nonhealthcare resources has not been thoroughly supported by evidence-based data. Despite the differences between healthcare and sociopolitical systems in various countries, more recent results from epidemiological research now clearly demonstrate the socioeconomic burden of fibromyalgia and its comorbidities. The costs of the disease, calculated in single studies and countries, allow estimates for populations in other countries. The alarming results highlight the urgent need both for more research (including pathophysiology and epidemiology) and for the acceptance of emerging treatment challenges.
\end{abstract}

Despite the increasing awareness of fibromyalgia (FM) as a socioeconomic burden, few data exist about its real costs resulting from utilization of both healthcare and nonhealthcare resources at different levels of the healthcare system and in different countries. In the previous issue of Arthritis Research \& Therapy, Sicras-Mainar and colleagues reported data from medical practice in a multicenter primary care setting in Spain, covering a primarily urban population [1]. The study analyzed the incremental costs of patients with FM as compared with a reference group of those patients in a healthcare provider's database with no claims related to FM (total $n=63,527$ adults, $n=1,081 \mathrm{FM}$ patients). In a subsample of 200 patients, self-perceived health and well-being were evaluated by applying the Fibromyalgia Impact Questionnaire, the Brief Pain Inventory, and the European Quality of Life five-item questionnaire.

For many years there has been agreement about the prevalence of FM being approximately 2 to $3 \%$. The most recent estimates from the United States suggest that FM affects about $5 \%$ of all women, and is the third most common rheumatic disorder after low back pain and osteoarthritis [2]. In a more recent study from Europe, the estimated overall prevalence of FM was $4.7 \%$ for chronic widespread pain, and was $2.9 \%$ when stronger pain and fatigue criteria were simultaneously used [3]. Many experts have shared their impressions about increasing prevalence and enormous costs; however, adequate evidence supporting these feelings for FM overall is missing.

There are few data on the costs of FM and the data differ. The approaches range from analyzing large databases to focusing on small samples. The set of assessment tools is not consistent, the reference groups are different, and some of the studies were performed more than 10 years ago. Finally, patterns of both medical care and sociopolitical procedures in various countries have to be considered. In a Canadian study from 1999, FM patients used about twice the health services and about twice the costs compared with a control group without widespread pain and compared with a control group from a local database [4]. A recent US study, published in 2007, calculated total healthcare costs three times higher in FM patients as compared with a control group of patients randomly selected from a health-insurance database [5]. In the main, the latter results were confirmed more recently [6]. Data acquisition about healthcare resource use by primary care patients in the UK analyzed the number of medical visits, and could demonstrate a reduction of such visits after diagnosis was established. The group did not, however, calculate costs [7]. A survey from the Netherlands found that the average annual disease-related total socioeconomic costs per patient were $€ 7,813$ for $F M$, $€ 8,533$ for chronic low back pain, and €3,205 for ankylosing spondylitis - the latter amount was calculated prior to the approval of biologicals for the treatment of ankylosing spondylitis [8].

The study from Sicras-Mainar and colleagues is the first calculation of incremental costs resulting from the use of healthcare and nonhealthcare resources by FM patients as

$\mathrm{FM}=$ fibromyalgia. 
compared with a reference group in a European primary care setting [1]. The mean incremental cost in FM patients exceeds those in the reference group by more than $€ 5,000$, of which only $€ 600$ was for the utilization of healthcare resources. FM patients displayed a higher prevalence of comorbidities than the reference population, had six more yearly medical visits, and showed a higher average of work days missed. They also revealed a higher use of pain-related medication (74\% of FM patients used nonsteroidal antiinflammatory drugs). Remarkably, the cost for pharmacological treatment represents only $8 \%$ of the total.

It has been calculated that a minimal increase in the Fibromyalgia Impact Questionnaire score (for instance, from 78.9 points to 81.5 points, stepping from one decile to the next - maximum score is 100) increases the costs by approximately $€ 865$ per year. This could also be shown to be true for pain severity. An increase of the Brief Pain Inventory score by one point (11-point Likert scale) increases costs by $€ 1,453$ per year. The higher the level of impact of the disease on patients' daily lives, the lower the changes in these levels have to be to increase costs dramatically. In agreement with results from another study [9], the presence of depression and/or anxiety symptoms significantly increased the total costs.

Obviously, there may be improvements associated with FM treatments which may not seem clinically meaningful to those unfamiliar with the condition, but which are clinically meaningful to FM patients. Recent FM research has described clinically relevant changes in this population for FIQ scores [10].

The data presented in this study should be an emergency signal for all those actively involved in decisions within and about the healthcare system(s) in each country. Assuming that $\mathrm{FM}$ is affecting up to $3 \%$ of the population, and using the data presented, these estimates have to be translated to annual incremental costs of up to approximately $€ 12$ billion $(€ 12,000,000,000)$ for a population of 80 million, for example - of which only $€ 960$ million (8\%) represent the costs of pharmacological treatment. Furthermore, assuming that patients benefit at least to some extent from pharmacological treatment and that this would decrease the costs due to utilization of healthcare and nonhealthcare resources, it is economically unwise to have no medication approved for the treatment of FM in Europe.

From the results presented, at least four pre-existing challenges have to be emphasized even more strongly.

First, there is still an unmet need for increasing the awareness of chronic pain and comorbidities in FM patients, the impact on their daily lives, and the resulting socioeconomic burden.

Furthermore, costs and the socioeconomic burden have to be analyzed in each country and in different healthcare systems and settings in order to improve evidence-based management of FM.

Third, further research has to be encouraged, targeting both subgroup analyses (impact of comorbidities on the outcome in different domains of the disease) and treatment efficacy (pharmacological and nonpharmacological) when adjusted to these subgroups.

Finally, since patients suffer now, and since the socioeconomic burden is evident, the healthcare system has to provide and to approve treatment according to the best efficacy data available to date.

\section{Competing interests}

The author declares that they have no competing interests.

\section{References}

1. Sicras-Mainar A, Rejas J, Navarro R, Blanca M, Morcillo A, Larios $\mathrm{R}$, Velasco S, Villarroya C: Treating patients with fibromyalgia in primary care settings under routine medical practice: a claim database cost and burden of illness study. Arthritis Res Ther 2009, 11:R54.

2. Lawrence RC, Felson DT, Helmick CG, Arnold LM, Choi H, Deyo RA, Gabriel S, Hirsch R, Hochberg MC, Hunder GG, Jordan GM, Katz JN, Kremers HM, Wolfe F; National Arthritis Work Group: Estimates of the prevalence of arthritis and other rheumatic conditions in the United States. Part II. Arthritis Rheum 2008, 58:26-35.

3. Branco JC, Bannwarth B, Failde I, Abello Carbonell J, Blotman F, Spaeth M, Saraiva F, Nacci F, Thomas E, Caubere JP, Le Lay K, Taieb C, Matucci-Cerinic M: Prevalence of fibromyalgia: a survey in five European countries. Semin Arthritis Rheum 2009 Feb 26. [Epub ahead of print]

4. White KP, Speechley $M$, Harth $M$, Ostbye $T$ : The London Fibromyalgia Epidemiology Study: direct health care costs of fibromyalgia syndrome in London, Canada. J Rheumatol 1999, 26:885-889.

5. Berger A, Dukes E, Martin S, Edelsberg J, Oster G: Characteristics and healthcare costs of patients with fibromyalgia syndrome. Int J Clin Pract 2007, 61:1498-1508.

6. Robinson RL, Birnbaum HG, Morley MA, Sisitsky T, Greenberg $\mathrm{PE}$, Claxton AJ: Economic cost and epidemiological characteristics of patients with fibromyalgia claims. J Rheumatol 2003, 30:1318-1325.

7. Hughes G, Martinez C, Myon E, Taieb C, Wessely S: The impact of a diagnosis of fibromyalgia on health care resource use by primary care patients in the UK: an observational study based on clinical practice. Arthritis Rheum 2006, 54:177-183.

8. Boonen A, van den Heuvel R, van Tubergen A, Goossens M, Severens JL, van der Heijde $D$, van der Linden S: Large differences in cost of illness and wellbeing between patients with fibromyalgia, chronic low back pain, or ankylosing spondylitis. Ann Rheum Dis 2005, 64:396-402.

9. Robinson RL, Birnbaum HG, Morley MA, Sisitsky T, Greenberg PE, Wolfe F: Depression and fibromyalgia: treatment and cost when diagnosed separately or concurrently. J Rheumatol 2004, 31:1621-1629.

10. Bennett RM, Bushmakin AG, Cappelleri JC, Zlateva G, Sadosky $A B$ : Minimal clinically important difference in the fibromyalgia impact questionnaire. J Rheumatol 2009, 36:1304-1311. 